\title{
Project Based Learning in Concrete Industry Project Management
}

\section{Dr. Anthony Torres, Texas State University, San Marcos}

Dr. Torres, a native of New Mexico, joined the Department of Engineering Technology (Concrete Industry Management program) in August 2013 where he teaches Concrete Construction Methods and a variety of Project Management courses. He received both of his graduate degrees, Ph.D. and M.S., in Civil Engineering (Structural), from the University of New Mexico. His B.S. degree, also in Civil Engineering, was obtained from New Mexico State University. Dr. Torres' research areas include the science and advancement of materials, such as concrete and cementitious materials, glass fibers, and composite materials. Dr. Torres' research interest also extends to the classroom, where he is constantly evolving his courses to provide the best education to his students.

Dr. Vedaraman Sriraman, Texas State University, San Marcos 


\title{
Project Based Learning in Concrete Industry Project Management
}

\begin{abstract}
A Project Based Learning (PBL) method has been implemented in a project management course that is geared towards the concrete industry. This course is a junior level course that is required for all Concrete Industry Management (CIM) students; a bachelor's of science degree that is offered at Texas State University. A PBL method was employed that utilized an actual concrete construction project from a local construction company. The students were introduced to the construction project early in the semester by the president of the construction company. The objective of this research is to determine the effectiveness of using actual, in-the-field projects that represent what the students will encounter once they graduate. The students received photographs of the concrete construction project, engineering documents and specifications, drawings and reports in addition to an introduction and question/answer period with the president of the company that implemented the project. Additionally, included in this study is a milestone formatting technique used for the project. The students were assigned milestone deliverables to be submitted shortly after the lecture covering the required topic was completed, in addition to one project packet due at the end of the semester. This ensured the topic was fresh in their memory when the required task was due and also provides an additional opportunity to improve on their project. Pre and post questionnaire analysis were provided to the students to acquire data regarding the implemented teaching method. The results showed that the students favored both the actual concrete construction project and the milestone deliverable method.
\end{abstract}

\section{Introduction to Project Based Learning}

Project-based learning (PBL) involves assignments that call for students to produce something, such as a process or product design, a computer code or simulation, or the design of an experiment and the analysis and interpretation of the data. The culmination of the project is normally a written or oral report summarizing what was done and what the outcome was ${ }^{1}$. Quite simply, PBL is a pedagogical model that organizes learning around projects.

Thomas suggests the following attributes in regard to the question "what must a project have in order to be considered an instance of PBL? ${ }^{2}$. These include:

- PBL projects are central, not peripheral to the curriculum.

- PBL projects are focused on questions or problems that "drive" students to encounter (and struggle with) the central concepts and principles of a discipline.

- Projects involve students in a constructive investigation.

- Projects are student driven to some extent.

- Projects are realistic, not school like.

PBL has been increasingly applied in higher education ${ }^{3}$. The use of PBL helps students develop a range of skills, including problem solving, group working, critical analysis, and communication ${ }^{4}$. In the past two decades PBL has found application in construction management programs. Some examples include: 
- At Plymouth University, U.K. PBL was used in a sustainable building course. The project involved a real world 'design and build' project for a waterfront development ${ }^{5}$.

- At Youngstown State University, PBL was used in a first course in LEED ${ }^{6}$.

- At the University of Colorado, PBL was used in the construction management of community building projects ${ }^{7}$.

- At Indiana University - Purdue University, PBL was used in courses entitled "Mechanical Systems in Buildings", "Construction Field Operations", and "Foundation Systems" .

In this paper the application of PBL in a project management course is described.

\section{Evolution of the Course and Details of PBL Implementation}

Understanding the Concrete Construction System is a required course for all Concrete Industry Management (CIM) majors and is a specialty class that is primarily focused on construction project management with an emphasis on the concrete industry. The students enrolled in this course are at the junior level and have previously taken the fundamentals of concrete and construction materials and processes courses. This course focuses on the management side of the concrete discipline. Additionally, the CIM program is a unique program, in that it specifically prepares individuals for employment in the concrete industry such as readymix concrete operations, contracting, material supply, precast and pre-stressed concrete, and engineering material quality control. The CIM program is also unique nationwide, in that there are only three other schools that offer the degree plan. The CIM program has been at Texas State University since 2009 and has been growing since its inception. The program is accredited by the National Steering Committee (NSC) of CIM, which consists of top-level executives of the national concrete industry. The NSC first developed the CIM degree in 1996 at Middle Tennessee State University and provides accreditation standards and criteria for all four schools. These accreditation criteria in turn translate into learning course outcomes that involve student understanding and application of the construction methodology, project participants, delivery methods, construction estimates and schedules. The learning outcomes ensure that the students will be successful professionally in the future. Therefore, it is important that the learning outcomes are emphasized in the course content. This teaching method is designed to accentuate the course outcomes through PBL and "milestone" task formatting.

A PBL method was employed that utilized an actual concrete construction project from a local construction company. The students were introduced to the required project on the first day of class. On this day the students were provided with the project requirements and any supplemental information including a pre-project questionnaire to gauge their learning and comprehension. At this time the students were also randomly assigned to groups of three. The additional supplemental information the students received included actual photographs of the concrete construction project, engineering documents such as structural drawings and engineer's report and assessment. On the second day of the course the project was further introduced with greater detail by the president of the construction company that implemented the project. The introduction included a question and answer session. This allowed the students to acquire a first hand knowledge of the project and access to a construction professional with over 30 years of 
experience. The hypothesis was that by using an actual, in-the field project, as opposed to a textbook problem, the students learning and understanding would be enhanced.

For this PBL method, the students were assigned milestone deliverables to be submitted shortly after the lecture covering the required topic was completed, as opposed to one project packet due at the end of the semester. This ensured the topic was fresh in their memory when the required task was due. Additionally, the practical relevance of each lecture topic was made apparent to the student. The realization of the one-to-one relationship between lecture and practice provides an incentive for students to treat the lecture with increased attention. The milestone deliverables were completed in the same three person groups, but were counted as homework assignments in the course. These deliverables were then graded and discussed in class and returned to the students. This allowed the students the opportunity to learn from their mistakes and be able to improve on their overall project.

The project involved concrete structural rehabilitation of an equipment warehouse completed in Bastrop, TX by Gaeke Construction Inc. in 2011. The warehouse, owned and used by a local electric cooperative company, was built to store large equipment and tools. In 2010, the owners noticed large cracks in the concrete slab that was due to a substantial upheave on the slab itself. It was determined that the warehouse was built on expansive clays that, when wet, expanded and forced the concrete slab upwards and caused the slab to crack and be uneven. Gaeke Construction Inc. was then hired to fix the problem. The rehabilitation of the slab included removal of a large portion of the slab from the center of the warehouse, removing a substantial portion of the expansive clays to minimize potential future expansion, replacing the expansive clays with select fill, epoxying and sealing the existing cracks on the existing concrete footers, and casting a new slab over the newly compacted select fill. The students were walked through this entire process by the President of Gaeke Construction and had access to the existing construction documents. The overall goal of the project is to have the student teams act as a general contractor "company" that is competing to win the job for their company. Each student "company" submitted their project as if they were submitting an actual bid package to the owner of the warehouse, which in this case the 'owner' was the professor of the course (Torres). The winning team was selected based on overall completeness, thoroughness, and organization of their project. The students were given no formal formatting guidelines and were left to their own professional judgment on formatting and presentation. During each milestone topic lecture the students were also presented with real-world construction documents not related to the project warehouse, but could be used as formal formatting aides. Since the students were provided the opportunity to see real-world construction documents they gained the experience and an understanding of each document that they would encounter in their future career. They also learned how to formally present, organize, and articulate the necessary information required for each construction document.

The project milestone breakdown is as follows:

\section{Milestone 1: Soil Characteristics and Recommendation}

The purpose of this milestone is to introduce and educate the students on a major factor that can affect concrete construction. Since most of concrete construction is placed on the soil, 
the type of soil and compaction of the soil can directly affect the concrete above. This project provided students' an opportunity to analyze soil characteristics and its impact on concrete structures. During the lecture given before this topic the students learn about soil properties and how they are analyzed. They also learn about the Unified Soil Classification System (USCS) ${ }^{9}$ and therefore can recommend a better soil to replace the expansive clay found below the warehouse project. The students are also provided with a real-life geotechnical report from another construction project in Texas. They are able to see and understand the contents of geotechnical reports and are also able to extract formatting and key information that needs to be presented to the owner of their project. In this section the students are required to assess the expansive clay situation of the project and present a solution, such as removal of the clay and replacing it with another type of soil.

\section{Milestone 2: Risk Assessment}

The risk assessment milestone is an important topic that is covered in this class, as construction risk is a big issue ${ }^{9}$. Before a construction company decides to submit a bid for a new project they must first assess the risk of simply devoting the time to prepare a new quality bid and secondly the risk from construction itself ${ }^{\ominus}$. Preparing a new construction bid for an owner requires time and resources and, typically, if the company wins the bid they don't get paid for this time 9 . The company needs to first decide if they have the time and resources to simply prepare the bid then secondly identify the major risks if they are selected as the company to perform the rehabilitation/construction. Companies do not want to enter a new construction contract to find a huge risk later on during the project implementation. The students learn the importance of construction risk and how to identify and assess the risk through an extensive lecture as well as a separate homework assignment on the topic. Students are provided with a real-world Request For Proposal (RFP) from a local owner requesting bids for a new medical facility to be built in Texas. The lecture consists of an extensive analysis on the RFP and the students are then asked to complete a homework assignment identifying specific construction risks related to the medical facility RFP. Once the homework is graded, the students are presented with the most prominent risks identified for this project and are asked to complete a similar analysis on their project.

\section{Milestone 3: Work Breakdown Structure (WBS)}

A Work Breakdown Structure (WBS) is a decomposition or "breakdown" of all the individual work activities into one structure resembling a categorized flowchart ${ }^{9}$. WBS are very important in construction project management as they help identify all the construction activities and categorize them under one major construction heading, such as earthwork, concrete construction, steel construction, etc. This is also an important step as it outlines the individual activities, which will eventually be scheduled for a specific construction time and date ${ }^{9}$. For this project milestone, the students are introduced to the topic and are walked through producing a WBS for a general concrete project. They are also presented with real-world WBS to use as a formatting aid when producing their own WBS for the project. The WBS is also a necessary step prior to completing the project estimate and the project schedule. 
Construction project estimating is also an important milestone to cover, as adequate cost estimating is they key to a profitable return on construction projects. The students are presented with an extensive lecture on how estimates are prepared in the construction industry first by hand then are presented with the various estimating software programs. In class estimating examples are also presented during the lecture in which real-world project documents are used to extract necessary information. This process educates the student on how real-world estimates are completed.

\section{Milestone 5: Project Schedule}

The last project milestone is the construction project schedule. Ultimately the project schedule determines when construction can start, how long each activity will take and lastly (and most importantly) when construction will finish. The students are first educated on how to produce construction schedules by hand during which activity real-world construction documents are used to produce the in-class examples. Once the students have a grasp on scheduling by hand, the lecture moves to a computer lab where they get trained on using the most readily used scheduling software: Microsoft Project and Primavera (P6). It is important that the students are educated on these two software packages as they will most likely be dealing either directly or indirectly with these software in their career. For this milestone the students are asked to produce a schedule for the warehouse rehabilitation project that accurately schedules each construction activity and adequately plans each construction activity accordingly.

Lastly, the students are required to give a presentation of their final project. The students were evaluated on their depth of knowledge of the project, technical information, clarity of presentation, final cost estimate, and construction schedule. Industry professionals were invited to the presentation as reviewers, which included the president of Gaeke construction.

\section{Data Collection and Analysis}

The primary data collection source from this study was a pre and post questionnaire that was distributed to the students on the first day of class and the last day of class, respectively. The questionnaire was scored on a scale of 1-10, 10 being the highest. The questionnaire consists of questions that are worded from the individual students' perspective, "I understand..." or "I can complete...". Therefore, the results reflect an individual student's comprehension or ability on each learning objective. The questions and their respective results are shown in Table 1. For better comparison the results have also been displayed in a bar chart in Figure 1. 
Table 1: Pre and post questionnaire questions and results.

\begin{tabular}{|c|c|c|c|c|c|}
\hline & \multicolumn{2}{|c|}{ Pre-Analysis } & \multicolumn{2}{|c|}{ Post-Analysis } & \multirow[b]{2}{*}{$\begin{array}{c}\text { Percent } \\
\text { Improvement }\end{array}$} \\
\hline Course Outcomes & Average & $\begin{array}{l}\text { Percent } \\
\text { In Favor }\end{array}$ & Average & $\begin{array}{l}\text { Percent } \\
\text { In Favor }\end{array}$ & \\
\hline $\begin{array}{l}\text { 1. I have an understanding of } \\
\text { the construction methodology, } \\
\text { project participants, and } \\
\text { delivery methods. }\end{array}$ & 4.6 & $56.94 \%$ & 6.7 & $83.33 \%$ & $37.62 \%$ \\
\hline $\begin{array}{l}\text { 2. I am able to perform } \\
\text { analysis on foundation's soil } \\
\text { characteristics. }\end{array}$ & 4.0 & $50.00 \%$ & 6.0 & $75.00 \%$ & $40.00 \%$ \\
\hline $\begin{array}{l}\text { 3. I am able to perform a } \\
\text { project risk assessment. }\end{array}$ & 4.6 & $56.94 \%$ & 6.7 & $83.33 \%$ & $37.62 \%$ \\
\hline $\begin{array}{l}\text { 4. I am able to construct a } \\
\text { detailed work breakdown } \\
\text { structure for construction } \\
\text { projects. }\end{array}$ & 4.2 & $52.78 \%$ & 6.6 & $81.94 \%$ & $43.30 \%$ \\
\hline $\begin{array}{l}\text { 5. I am able to construct } \\
\text { estimates for proposed } \\
\text { construction projects. }\end{array}$ & 4.3 & $54.17 \%$ & 6.2 & $77.78 \%$ & $35.79 \%$ \\
\hline $\begin{array}{l}\text { 6. I am able to construct a } \\
\text { project schedule. }\end{array}$ & 4.2 & $52.78 \%$ & 6.4 & $80.56 \%$ & $41.67 \%$ \\
\hline
\end{tabular}

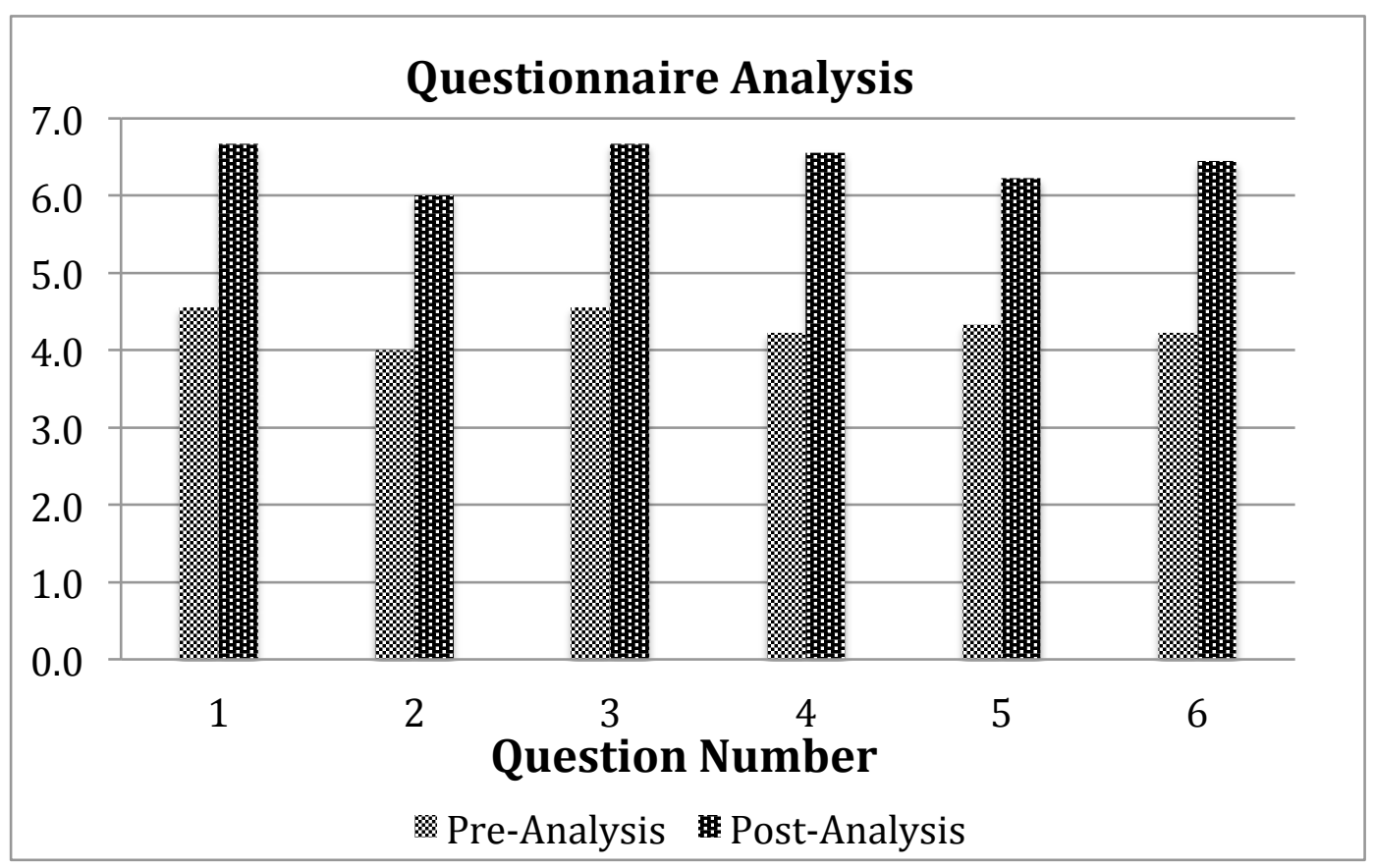

Figure 1: Pre and post questionnaire analysis results. 
As shown in Table 1 and Figure 1, the results show improvement in every category. This is an expected outcome, as most of the students do not have a construction project management background. Even the students, who may have a construction background, may still not have the knowledge of every element outlined in the questionnaire. Question 1 is a question directly relating to the program requirements stipulated by the NSC, which relates to the understanding of construction project participants, organization, and delivery methods. This question was included as it is an essential concept in construction project management and is needed to proceed through the milestones of the project, even though there's no corresponding milestone directly relating to project participants. Question 1 showed an improvement of understanding by $37.62 \%$. Question 2 considers the students' understanding of soil for foundation conditions. Soil analysis is not typically discussed in traditional project management textbooks ${ }^{9}$, but is included in this course and in the project as it is the underline problem and cause of the structural failure on the warehouse investigated in the project. It is also the opinion of the authors that understanding soil conditions and problems that could arise from unsatisfactory soil conditions is essential knowledge for construction industry professionals. The lecture regarding this topic included discussions on soil characterization using USCS data sheets, the Atterberg limits for fine-grained soil, and existing geotechnical reports from a local construction site. From this lecture, the students were required to complete Milestone 1. The questionnaire analysis shows that the students' understanding on this topic increased by $40 \%$ by the end of the semester. Question 3 assess the students understanding of determining potential risks in a construction project and how to prevent risks. A brief summary of this lecture includes a discussion on RFP's from owners and a description of the information that is included in these documents. The students are also walked through a lecture from the textbook regarding project risks and how to prevent them. Subsequently, the students are walked through some identified risks in an example RFP and asked to complete a homework assignment on finding potential risks in an actual RFP. The post analysis showed an increase in understanding on this milestone of $37.62 \%$. Question 4 probed the students understanding on their ability to understand and produce a construction WBS. This milestone produced the highest results from the post-analysis at a percent improvement of $43.30 \%$. This may be due to the fact that WBSs are closely related to flow charts, which the students have being asked to produce in other classes. Extensive examples and an in-class walkthrough with the students could have also led to the high increase of understanding. Milestone 4 and question 5 related to the students understanding of producing a construction estimate. This question resulted in the lowest percent improvement of $35.79 \%$. This is partially believed to be due to the complexity of construction estimates and the lack of existing knowledge of the students. Due to this result, the authors feel that additional time could be devoted to the estimating topic. Lastly, question 6 focuses on the student understanding and ability to produce a construction schedule. Multiple lectures are produced for this topic that include introduction to project schedules, hand calculations, and computer based scheduling software. This category showed a percent improvement of $41.67 \%$, which is considerable given the lectures provided for this topic. The results show a percent increase in all categories with an overall average of the percent increase being 39.33\%. It should be mentioned again that these results reflect each student's personal feelings toward the comprehension of each learning objective. For example, Outcome 5 shows only a $77.78 \%$ in favor of comprehension. This does not reflect that the remaining $22.22 \%$ of students failed the learning objective. This result reflects a $77.78 \%$ personal understanding of the topic. A student may have passed the assignment, but may still not be fully comfortable with the topic. The authors realize that these are subjective 
results and plan to implement individual objective results such as exam question grades, assignment grades, and milestone grades in future iterations of this study.

\section{Conclusions and Recommendations}

A PBL approach was employed that utilized an actual concrete construction project from a local construction company. The objective of this study was to determine the effectiveness of using actual, in-the field projects that represent what the students will encounter once they graduate. The students were introduced to the construction project early in the semester by the president of the construction company. The students received photographs of the concrete construction project, engineering documents, drawings and reports in addition to an introduction and question period with the president of the company that completed the project. Additionally, implemented in this study is a milestone formatting of the project. The students were assigned milestone deliverables to be submitted shortly after the lecture covering the required topic was completed, in addition to one project packet due at the end of the semester. This ensured the topic was fresh in their memory when the required task was due and also provides an additional opportunity to improve on their project. Students were also able to appreciate the importance of theoretical principles and concepts covered in the class room as the application of these principles and concepts were crucial for milestone and project completion. Thus, the active participation of students in the lecture classes was secured. The analysis of the questionnaire revealed that the students have learned essential construction project management skills using the PBL method implemented in this class. The increase in comprehension from pre to post questionnaire analysis revealed that this PBL teaching method, which incorporated actual, in the field projects was effective. This was the second time that this method was implemented in this course; however, this was the first semester that any statistical data was captured to investigate the effectiveness of this study. Additionally, the milestone formatting of the project was newly implemented in the second iteration of this study.

The authors realize that it may be difficult to identically replicate this case study at a reader's own institution due to the specific warehouse example. However, the fundamental pedagogical approach of this study can be implemented. The milestone formatting technique is not unique to the authors' institution and can be adapted to any topic and any course choosing to implement a PBL method. For a project management type classroom, the milestone objectives are directly translatable and the description and requirements of each milestone are described above. However, the unique aspect of this study to the authors' institution is the specific real world project used. If a reader desires to implement this study in his or her own classroom the authors recommend identifying a local construction company and securing appropriate past projects. This study used a 'small scale' construction project to reduce the project complexity in order to ease the students into understanding the project. This study also uses a concrete rehabilitation project with demolition and crack epoxying, however that is not absolutely necessary for other implementations. This specific project was also selected for the CIM course due to its focus on concrete construction and rehabilitation. Therefore, the concrete portion isn't as necessary in the instance of general construction project management courses.

Future recommendations for this study are to add additional content to the questionnaire

regarding the students' preference of the milestone formatting. Currently, there is no data on the 
impact of this method on the students learning. The authors feel that this teaching method is more effective within PBL as the students learn the individual topic, then immediately apply the knowledge to the project as opposed to applying the learned techniques at the end of the semester when the project is due. Additionally, the authors plan to provide additional data points regarding the students' grades on the milestone assignments versus the grades of the overall project. This will require a grading rubric as a baseline, so that each milestone and the individual portion of the project are graded with the same criteria for better comparison. During the current iteration of this study, the milestone assignments were graded leniently, as the introduction of a new assignment might engender some disturbance to a "well-oiled machinery". A high degree of comments were provided on each milestone assignment to provide direction and areas of improvement for the final project. Lastly, additional examples will be presented during the estimating chapter, as this was the area with the least improvement.

\section{References}

1. Prince, M. and Felder, R. (2007) The Many Faces of Inductive Learning, Journal of College Science Teaching,

2. Thomas, J.W. (2000) A Review of Research on Project-Based Learning, The Autodesk Foundation, San Rafael, CA.

3. Pan, W. and Allison, J. (2010) Exploring Project and Problem Based Learning in Environmental Building Education by Integrating Critical Thinking, International Journal of Engineering Education, Volume 26, No. 3.

4. Overton, T. (2003) Key aspects of teaching and learning in experimental sciences and engineering, In Fry, H., Ketterridge, S. and Marshall, S. (eds.) A Handbook for Teaching and Learning in Higher Education: Enhancing Academic Practice, $2^{\text {nd }}$ Edn. London: Kogan Page.

5. Pan, W. and Garmston, H. (2012) Enhancing Project-Based Learning in Sustainable Building by Incorporating Learning Technology, $48^{\text {th }}$ ASC International Conference Proceedings.

6. Korenic, R. (2014) Assessing the Effectiveness of Problem and Project Learning in a Green Building Design and Construction Course using ETAC Criteria. Journal of Sustainability Education, June 2014.

7. Cinowsky, P.S., Brown, H., Szajnman, A., and Realph, A. (2006) Developing Knowledge Landscapes through Project Based Learning, ASCE Journal of Professional Issues in Engineering Education and Practice, Volume 132, No.2.

8. Erdogan, M.S., (1998) Design of the Learning Environment : Professional Project-Based Learning in Construction Education, 1998 ASEE Annual Conference Proceedings.

9. Gould, F., Joyce, N., Construction Project Management $4^{\text {th }}$ Ed. 2014, Prentice Hall 